\title{
A LIBERDADE SINDICAL NA CONSTITUIÇÃO FEDERAL DE 1988 EM CONTRAPOSIÇÃO À CONVENÇÃO Nº 87 DA ORGANIZAÇÃO INTERNACIONAL DO TRABALHO
}

TRADE UNION FREEDOM IN THE 1988 FEDERAL CONSTITUTION AGAINST CONVENTION NO. 87 OF THE INTERNATIONAL LABOR ORGANIZATION

lara Marthos ÁGUILA ${ }^{1}$

Letícia Perondi COSTA ${ }^{2}$

ISSUE DOI: $10.21207 / 1983.4225 .942$

\begin{abstract}
RESUMO
O objetivo do presente artigo é analisar a liberdade sindical adotada na Constituição da República Federativa do Brasil de 1988 em comparação com o modelo preconizado pela Convenção $\mathrm{n}^{\circ} 87$ da Organização Internacional do Trabalho (OIT). Para isso, inicialmente serão abordados os aspectos históricos que levaram ao surgimento dos sindicatos, posteriormente o artigo aborda questões sobre a estrutura e organização sindical, bem como a atuação sindical no exercício das funções primeiras do sindicato. No cotejo entre a liberdade sindical prevista na Constituição Federal de 1988 e a liberdade sindical indicada na Convenção n ${ }^{\circ} 87$ da OIT será demonstrado maior rigor da Carta Constitucional a ponto de limitar e restringir a liberdade sindical, tendo em vista a imposição do princípio da unicidade

\footnotetext{
${ }^{1}$ Doutoranda em Direito pela pela Faculdade Autônoma de Direito (FADISP). Possui graduação em Direito pela Universidade Estadual Paulista Júlio de Mesquita Filho (1990) e mestrado em Direito pela Universidade Estadual Paulista Júlio de Mesquita Filho (1998). Atualmente é professora titular da Faculdade de Direito de Franca. Foi professora titular da Universidade de Franca e professora celetista na Universidade Estadual Paulista - Unesp, campus de Franca. Tem experiência na área de Direito, com ênfase em Direito do Trabalho. É advogada trabalhista atuante. http://lattes.cnpq.br/ 0671409528318178 .

${ }^{2}$ Graduada em Direito pela Faculdade de Direito de Franca.
} 
sindical, que impede a criação de mais de um sindicato da mesma categoria dentro da mesma base territorial; a imposição do critério da categoria para a constituição de um sindicato. A liberdade sindical proposta pela OIT é ampla, sem restrições, não estabelecendo critérios para a constituição do sindicato e sugerindo a pluralidade sindical como forma autêntica e democrática de representação sindical. $\mathrm{O}$ artigo demonstra que os preceitos adotados pela Convenção $n^{\circ} 87$ da OIT, em parte, são conflitantes com a nossa Constituição Federal, razão pela qual, a convenção internacional não foi ratificada pelo Brasil.

Palavras-chave: Sindicatos. Liberdade Sindical. Autonomia sindical. Convenção no 87 da OIT.

\begin{abstract}
The purpose of this paper is to analyze the freedom of association adopted in the 1988 Constitution of the Federative Republic of Brazil in comparison with the model advocated by Convention No. 87 of the International Labor Organization (ILO). To this end, initially the historical aspects that led to the emergence of unions will be addressed, later the article will address questions about union structure and organization, as well as union action in the exercise of the union's primary functions. In the comparison between the freedom of association provided for in the Federal Constitution of 1988 and the freedom of association indicated in ILO Convention No. 87, a more rigorous Constitutional Charter will be demonstrated to the point of limiting and restricting freedom of association, in view of the imposition of the principle of union unity, which prevents the creation of more than one union of the same category within the same territorial base; the imposition of the category criterion for the constitution of a union. The freedom of association proposed by the ILO is broad, without restrictions, not establishing criteria for the constitution of the union and suggesting union plurality as an authentic and democratic form of union representation. The article demonstrates that the precepts adopted by ILO Convention 87, in part, are in conflict with our Federal Constitution, which is why the international convention has not been ratified by Brazil.
\end{abstract}

Keywords: Unions. Union Freedom. Union autonomy. ILO Convention No. 87.

\title{
1 INTRODUÇÃO
}

O presente artigo se propõe analisar a liberdade sindical adotada no artigo $8^{\circ}$, da Constituição Federal de 1988 e a liberdade sindical preceituada pela Organização Internacional do Trabalho (OIT), mais precisamente em sua Convenção $\mathrm{n}^{\circ} 87$. Os diferentes modelos de liberdade sindical previstos na Constituição Federal e na Convenção da OIT permitem abordagem analítica e crítica sobre a conveniência de um modelo em detrimento do outro.

A liberdade sindical e autonomia sindical são princípios fundamentais que regem as relações coletivas de trabalho, manifestando a expressão da vontade de trabalhadores e empregadores na defesa de seus direitos e interesses. Ambas representam aspecto democrático na criação e funcionamento de entidade sindical.

No mesmo sentido, a atuação sindical somente atenderá suas principais funções, representativa e negocial, na hipótese de livre atuação 
dos sindicatos, em respeito à liberdade sindical. Ainda que, os sindicatos representem interesses dos empregadores (categoria econômica) e interesses dos trabalhadores (categoria profissional), o destaque fica no sindicato dos trabalhadores, tendo em vista a natural preocupação pela proteção de direitos trabalhistas e condições de trabalho dos obreiros.

Para melhor compreensão do tema faz-se necessário percorrer, ainda que de forma sucinta, algumas questões propedêuticas, como a apresentação de conceitos, abordagem histórica da atividade sindical e, propriamente, a análise da liberdade sindical na Constituição Federal de 1988 e na Convenção $\mathrm{n}^{\circ} 87$ da OIT, tratando da unicidade sindical e pluralidade sindical respectivamente.

Considerando o objeto da análise realizada neste artigo, a abordagem se limita ao movimento sindical e sindicatos no Brasil.

\section{SINDICATOS}

Sindicato é o ator social mais relevante no direito coletivo do trabalho, na medida em que, como sujeito do direito coletivo tem legitimidade para representar e defender os interesses individuais e coletivos da categoria por ele representada. Os sindicatos são "entes de direito privado, representam particulares, são criados exclusivamente por iniciativa destes, para a representação de defesa dos seus interesses". 3 Sindicato é pessoa jurídica de direito privado.

Sérgio Pinto Martins conceitua sindicato como uma associação composta por pessoas físicas ou jurídicas, as quais exercem atividade econômica ou profissional, e que visa defender os interesses coletivos e individuais dos membros da sua respectiva categoria. ${ }^{4}$

Embora o sindicato seja representativo da categoria econômica (patronal) e da categoria profissional (dos trabalhadores) exerce maior força de atração para análise e estudo o movimento sindical dos trabalhadores, a ponto de alguns autores definirem sindicato como entidade representativa dos trabalhadores. A centralidade se justifica no fato de maior necessidade representativa voltada para os obreiros e não para as empresas, mesmo porque, estas podem ser consideradas sujeito coletivo

\footnotetext{
${ }^{3}$ NASCIMENTO, Amauri Mascaro. Direito sindical. 2 ed., São Paulo: LTr, 1991, p. 216.

${ }^{4}$ MARTINS, Sérgio Pinto. Direito do trabalho. 30. ed. São Paulo: Atlas, 2014. p. 791.
} 
nas relações de trabalho sem a necessidade da presença do sindicato patronal.

Nesse sentido, Maurício Godinho Delgado conceitua sindicato:

Sindicatos são entidades associativas permanentes, que representam trabalhadores vinculados por laços profissionais e laborativos comuns, visando tratar de problemas coletivos das respectivas bases representadas, defendendo seus interesses trabalhistas e conexos, com o objetivo de lhes alcançar melhores condições de labor e vida. ${ }^{5}$

O sindicato configura uma associação de classe com poderes que consistem na defesa dos direitos e interesses coletivos ou individuais de uma categoria, seja em questões judiciais ou administrativas, conforme preceitua o artigo $8^{\circ}$, III, da Constituição Federal.

Na visão de José Cláudio Monteiro de Brito Filho, o sindicato consiste em uma entidade sindical composta por pessoas jurídicas e pessoas físicas, com dever de representação, tutela e gestão de interesses da respectiva categoria. ${ }^{6}$

\subsection{ALGUNS ASPECTOS HISTÓRICOS SOBRE MOVIMENTO SINDICAL.}

O nascimento do sindicalismo pode ser mais claramente vislumbrado a partir da segunda metade do século XVIII, com a Revolução Industrial e a posterior busca por melhores condições de trabalho, na qual se incluem as lutas de classes e a integração de trabalhadores que almejavam trabalho mais digno.

A Revolução Industrial revelou-se cenário propício para a união dos trabalhadores assalariados e despertar da consciência coletiva do operariado. O sistema de produção trouxe a mão-de-obra para dentro das fábricas e essa concentração facilitou a comunicação e mobilização dos trabalhadores. Paralelamente, o modelo capitalista de produção maximizado na Revolução Industrial permitiu que os empregadores impusessem condições de trabalho desumanas e indignas. $\mathrm{O}$ contexto foi decisivo para que os trabalhadores percebessem que somente por meio da

\footnotetext{
${ }^{5}$ DELGADO, Maurício Godinho. Curso de direito do trabalho. 18. ed. São Paulo: LTr, 2019. p. 1590. ${ }^{6}$ BRITO FILHO, José Cláudio Monteiro de. Direito sindical. 3. ed. São Paulo: LTr, 2009. p. 100.
} 
união teriam força necessária para oposição à exploração nas relações de trabalho que dominava o período.

Muito embora as formas de associações fossem inicialmente proibidas os trabalhadores, cada vez mais inconformados com suas condições de trabalho, uniam-se em grande massa para a defesa de seus interesses, movidos por sua indigna situação de labor.

Amauri Mascaro Nascimento esclarece que: "Não se pode pôr em dúvida que o sindicalismo nasceu tendo em vista a situação dos trabalhadores, neles provocando um sentimento de solidariedade e um espírito de união que os animou à luta em torno de melhores horizontes". ?

Inicialmente a associação dos trabalhadores aos sindicatos foi proibida, depois de algum tempo passou a ser tolerada, para finalmente ser reconhecida como legítima e regulamentada no ordenamento jurídico de diversos países, a exemplo da França, com a Lei Waldeck-Rousseau (1884); México, com a Constituição do México (1917) e a Constituição de Weimar (1919). ${ }^{8}$

A partir do processo de reconhecimento o sindicalismo foi tomando proporções cada vez maiores, culminando com a Declaração Universal dos Direitos do Homem, a qual tratou de pontos acerca do Direito Sindical, em seus artigos XX e XXIII ${ }^{9}$, e com a Organização Internacional do Trabalho (OIT), organismo especial, vinculado à Organização das Nações Unidas, que reconheceu de fato o direito às organizações coletivas. Com o advento da OIT, a liberdade sindical passou a ser impulsionada por meio de Convenções, especialmente com a Convenção $n^{\circ} 87$, a qual trata especificamente da liberdade sindical e da proteção ao direito sindical $^{10}$.

No Brasil as primeiras regulamentações legais reconhecendo o direito à sindicalização foram o Decreto $n^{\circ}$ 979, de 1903, que permitiu a reunião dos profissionais da agricultura e das indústrias rurais, e o Decreto $\mathrm{n}^{\circ} 1.637$, de 1907, que forneceu organização ao sindicalismo de caráter urbano, por meio da reunião de profissionais cujas profissões fossem

\footnotetext{
${ }^{7}$ NASCIMENTO, Amauri Mascaro. Direito sindical. 2. ed. São Paulo: Saraiva, 1991. p. 24.

${ }^{8}$ BRITO FILHO, José Cláudio Monteiro de. Direito sindical. 3. ed. São Paulo: LTr, 2009. p. 54.

${ }^{9}$ Artigo XX I) Todo o homem tem direito à liberdade de reunião e associação pacíficas. II) Ninguém pode ser obrigado a fazer parte de uma associação. Artigo XXIII [...]IV) Todo o homem tem direito a organizar sindicatos e a neles ingressar para proteção de seus interesses.

${ }^{10}$ BARROS, Alice Monteiro de. Curso de direito do trabalho. 7. ed. São Paulo: LTr, 2011. p. 962.
} 
conexas ou similares ${ }^{11}$. Na década de 1930 inicia-se a fase intervencionista estatal no direito sindical que deixou reflexos até a atual fase do sindicalismo nacional.

A Carta ditatorial de 1937, ao consagrar o princípio da unicidade sindical, impedia a plena liberdade sindical, ao impor que apenas poderia haver um único sindicato da mesma categoria profissional ou econômica dentro da mesma base territorial - unicidade essa que resta configurada ainda hoje no ordenamento jurídico, mesmo que tenha se originado em épocas de restrições de liberdade. O controle sobre as entidades sindicais restava cada vez mais configurado e intensificado, oriundo de um sistema profundamente corporativista. $^{12}$

A Consolidação das Leis do Trabalho (CLT), Decreto-Lei $\mathrm{n}^{\circ}$ 5.452 , de 1943, incorporou os preceitos sindicais que haviam sido delimitados pelo Governo Getulista, mantendo a mesma concepção corporativista dos sindicatos que permeou no Brasil, especialmente após a década de 1930.

A Constituição Federal de 1988 definitivamente rompe com o perfil autoritário dos governos ditatoriais anteriores e efetiva processo mais democrático, garantindo o direito à associação profissional ou sindical, como está nítido no caput de seu artigo $8^{\circ}$. Porém, não obstante a adoção de garantias sindicais e democratização na organização sindical, a unicidade sindical foi mantida no inciso II, do artigo $8^{\circ}$, e representa resquício corporativista da década de 1930 , não compatível com a plena liberdade sindical.

\section{$2.2 \quad$ FUNÇÕES DO SINDICATO}

A entidade sindical possui diferentes funções vinculadas à sua própria razão de ser e existência. Dentre as principais funções destaca-se a primeira e principal função do sindicato, que é a função representativa, vale dizer, a função de representar os interesses individuais e coletivos da categoria que o constituiu. A função representativa está prevista na norma constitucional, no inciso III, do artigo $8^{\circ}$.

\footnotetext{
${ }^{11}$ RUSSOMANO, Mozart Victor. Princípios gerais do direito sindical. 2. ed. Rio de Janeiro: Forense. 1998, p. 31.

${ }^{12}$ RUSSOMANO, Mozart Victor. Princípios gerais do direito sindical. 2. ed. Rio de Janeiro: Forense. 1998, p. 33.
} 
Outra importante função dos sindicatos, decorrente da função primeira, é a função negocial. O sindicato tem a prerrogativa de participar de negociação coletiva, de modo que, somente o sindicato (e na sua falta, entidade sindical de grau superior) está legitimado para estabelecer negociação coletiva com finalidade de conquistar melhores condições de trabalho ou estabelecer condições de trabalho. O inciso VI, do artigo $8^{\circ}$ da Constituição Federal, obriga a participação dos sindicatos na negociação coletiva. O entendimento pacificado é de que essa obrigatoriedade se limita ao sindicato da categoria profissional, tendo em vista que a empresa é considerada ser coletivo com representatividade suficiente para participar em condições de igualdade na negociação coletiva voltada para acordo coletivo.

A função normativa é decorrente da função negocial. Trata-se de função que cria norma jurídica sobre condições de trabalho, ou seja, revelase meio de produção de direito, cada vez dotado de maior relevância no ordenamento jurídico e que se manifesta através de convenções coletivas e de acordos coletivos de trabalho. ${ }^{13}$ É por meio dessa função que a entidade sindical cria normas com o intuito de satisfazer os interesses e direitos da categoria que representa. A Constituição Federal não apenas reconhece as convenções coletivas e os acordos coletivos de trabalho como também incentiva a negociação coletiva em diversos dispositivos, como os incisos VI, XIII, XIV, e XXVI, do artigo $7^{\circ}$.

$\mathrm{O}$ sindicato também possui função assistencial prestando serviços necessários aos membros da categoria que representa. É uma função que se encontra presente desde os tempos mais remotos da organização sindical. ${ }^{14}$ Esses serviços podem ser exemplificados como serviços médicos, jurídicos e educacionais, que não se consistem em deveres dos sindicatos, mas sim em prerrogativas que eles podem assumir em benefício de seus representados.

Além das funções indicadas é possível identificar outras funções, que deixam de ser mencionadas em razão da temática desenvolvida neste artigo.

\section{ESTRUTURA E ORGANIZAÇÃO SINDICAL NO BRASIL}

\footnotetext{
${ }^{13}$ NASCIMENTO, Amauri Mascaro. Direito sindical. 2. ed. São Paulo: Saraiva, 1991. p. 202.

${ }^{14}$ NASCIMENTO, Amauri Mascaro. Direito sindical. 2. ed. São Paulo: Saraiva, 1991. p. 203-204.
} 
A estrutura interna do sindicato e sua organização sindical estão diretamente relacionadas ao princípio da liberdade sindical, visto que o sindicato é por essência o sujeito do direito coletivo do trabalho, via de consequência, o movimento sindical desde a criação do sindicato e sua atuação reflete a liberdade sindical.

$\mathrm{O}$ inciso I, do artigo $8^{\circ}$ da Constituição Federal adota expressamente o princípio da autonomia sindical. Mozart Victor Russomano esclarece que a autonomia sindical consiste no direito dos sindicatos de organizarem livremente sua estrutura interna, sendo a eles permitido votar seu estatuto independentemente de haver modelos legais que devam ser adotados como forma de orientação. ${ }^{15}$

No entanto, a legislação infraconstitucional apresenta manifestações de intervenção do Estado na organização sindical. Por determinação legal expressa na CLT, os sindicatos são compostos de três órgãos, que são a Assembleia Geral, o Conselho Fiscal e a Diretoria. O primeiro é órgão deliberativo, composto pelos associados e possui a responsabilidade de votar e decidir as questões afetas ao sindicato. O Conselho Fiscal é o órgão incumbido de fiscalizar a gestão financeira do sindicato, ou seja, do recebimento das contribuições e aplicação dessas importâncias de acordo com os seus fins. A Diretoria consiste em um órgão executivo, cuja função é a de administrar e organizar o sindicato, bem como expressar os interesses da categoria. ${ }^{16}$

No mesmo sentido, a Consolidação das Leis do Trabalho, em seu artigo 522, delimita o máximo de sete e o mínimo de três membros para composição da Diretoria, e o número de três membros para a composição do Conselho Fiscal, além de estipular que ambos os órgãos serão eleitos pela Assembleia Geral.

A Constituição Federal de 1988 ao consagrar o princípio da autonomia sindical veda ao Estado interferir na criação e funcionamento do sindicato. A autonomia sindical assegura liberdade de administração dos sindicatos, não sendo permitido ao Poder Público interferir na organização sindical, conforme dispõe o inciso I, do artigo $8^{\circ}$, da Constituição Federal.

Após a promulgação da Carta Constitucional a doutrina começou a discutir sobre a compatibilidade de dispositivos da CLT com o

\footnotetext{
${ }^{15}$ RUSSOMANO, Mozart Victor. Princípios gerais do direito sindical. 2. ed. Rio de Janeiro: Forense, 1998. p. 72.

${ }^{16}$ MARTINS, Sérgio Pinto. Direito do trabalho. 30. ed. São Paulo: Atlas, 2014. p. 810.
} 
novo texto constitucional. $\mathrm{O}$ entendimento predominante indica que os dispositivos da CLT que representam interferência do Estado no funcionamento do sindicato não foram recepcionados pela Constituição Federal de 1988, inclusive o artigo 522 da CLT. Na mesma direção, Amauri Mascaro Nascimento esclarece que tendo em vista a proibição de intervenção estatal na organização sindical, não mais pertence à lei apontar quais serão os órgãos integrantes da estrutura sindical, pois, do contrário, ocorrerá desrespeito ao princípio constitucional da liberdade de administração. ${ }^{17}$

Embora acredite que nem todas as estipulações legais causariam interferências nos sindicatos, pois muitas delas podem perfeitamente configurar-se sem que haja cerceamento de liberdade, José Cláudio Monteiro de Brito Filho também defende o posicionamento de que algumas delas são restritivas para a autonomia sindical, a exemplo do número de membros por órgão. E desse modo, o autor entende que a administração dos sindicatos deve ocorrer da maneira que os mesmos julgarem pertinente as suas finalidades. ${ }^{18}$

Vale ressaltar que, na visão de Maurício Godinho Delgado, a autonomia sindical consiste em uma autonomia relativa, pois embora o autor concorde que em certos aspectos o texto celetista vá de encontro a não intervenção estatal nos sindicatos, visto que são os estatutos que terão melhores condições de definir as organizações internas sindicais, o exercício abusivo dos direitos é vedado em qualquer circunstância, relativizando, portanto, a autonomia. ${ }^{19}$

Aos sindicatos é permitida a total organização de sua estrutura, delimitando órgãos, funções e número de membros em cada órgão. Desse modo, sua estrutura interna não precisa se limitar exclusivamente à Diretoria, ao Conselho Fiscal e à Assembleia Geral, possibilitando maior amplitude de funções. Conforme se depreende do inciso IV, do artigo $8^{\circ}$ da Constituição Federal, o único órgão que necessariamente precisa permanecer é a Assembleia Geral. ${ }^{20}$

O Tribunal Superior do Trabalho manifesta entendimento, exposto no item II, da Súmula $\mathrm{n}^{\mathrm{o}} 369$, de que o artigo 522 da CLT foi recepcionado pela Constituição Federal apenas para limitar a quantidade

\footnotetext{
${ }^{17}$ NASCIMENTO, Amauri Mascaro. Direito sindical. 2. ed. São Paulo: Saraiva, 1991. p. 198.

${ }^{18}$ BRITO FILHO, José Cláudio Monteiro de. Direito sindical. 3. ed. São Paulo: LTr, 2009. p. 125.

${ }^{19}$ DELGADO, Maurício Godinho. Curso de direito do trabalho. 18. ed. São Paulo: LTr, 2019. p. 1605.

${ }^{20}$ BARROS, Alice Monteiro de. Curso de direito do trabalho. 7. ed. São Paulo: LTr, 2011. p. 978.
} 
de membros estáveis na qualidade de dirigentes sindicais, nos termos do artigo 543, $\S 3^{\circ}$, da CLT.

É preciso dizer, por outro lado, que a ofensa ao princípio constitucional da autonomia sindical expressa na regulamentação legal no que tange à estrutura interna do sindicato não está plenamente pacificada na doutrina, uma vez que existem autores ${ }^{21}$ que sustentam que as estipulações legais, como as constantes no artigo 522, da CLT, não trariam prejuízo à autonomia sindical por não representarem formas de intervenções abusivas.

\subsection{UNICIDADE E PLURALIDADE SINDICAL}

A unicidade sindical consiste na obrigatoriedade de existir apenas um único sindicato representativo da mesma categoria profissional ou econômica dentro da mesma base territorial. O modelo da unicidade sindical foi mantido em nossa Constituição Federal, não obstante representar uma herança do corporativismo vigente no Brasil na década de 1930 e carregar traços incompatíveis com as convicções democráticas abraçadas pela Constituição Federal de 1988. Na opinião de Francisco Antônio de Oliveira, a imposição por lei de um sindicato único acaba por torna-lo mais frágil, pois acaba limitando sua liberdade que, em tese, deveria ser regida por total amplitude. ${ }^{22}$

$\mathrm{O}$ inciso II, do artigo $8^{\circ}$, da Constituição Federal não apenas impôs a unicidade sindical como também definiu o tamanho mínimo de uma base territorial em um município. Ainda, determinou como critério para a criação de sindicato a categoria, mantendo a mesma ideia da década de 1930.

No Brasil, o princípio da unicidade sindical é adotado em todo o sistema confederativo, ou seja, ó obrigatório para os sindicatos, para as federações e para as confederações. Trata-se de um sistema que não permite aos obreiros formarem uma coletividade natural, organizando-se

\footnotetext{
${ }^{21}$ MARTINS, Sérgio Pinto. Direito do trabalho. 30. ed. São Paulo: Atlas, 2014.

${ }^{22}$ OLIVEIRA, Francisco Antônio de. Manual de direito individual e coletivo do trabalho. 2. ed. São Paulo: RT, 2000. p. 476.
} 
de forma livre e conforme sua vontade, ficando sempre vinculados a um único sindicato por categoria. ${ }^{23}$

Joselita Nepomuceno Borba destaca que a unicidade sindical é um dos elementos que permaneceram como fruto do corporativismo, ainda que o sindicato tenha obtido grande autonomia organizacional com o advento da Constituição Federal de 1988. Conforme o entendimento da autora, o sistema sindical atual é dotado de liberdade parcial, que não permite a ratificação da Convenção $\mathrm{n}^{\circ} 87$ da OIT, a qual trata da liberdade sindical de maneira muito mais ampla em comparação a que ocorre no Brasil. Dessa maneira, em sua visão, enquanto o país não vivenciar uma forma de liberdade mais plena, o sindicato não poderá desempenhar seu papel de maneira totalmente eficaz, ocorrendo prejuízo em seu sistema de representação. ${ }^{24}$

Em contraposição à unicidade sindical está a pluralidade sindical, na qual podem existir dois ou mais sindicatos de uma determinada categoria em uma mesma base territorial. Esse princípio é usado em diversos países que, ao contrário do Brasil, não limitam o número de sindicatos para representar trabalhadores e empregadores de uma mesma categoria.

Amauri Mascaro elenca que em um sistema de pluralidade sindical, a liberdade sindical pode existir de maneira ampla ou restrita. Existirá totalmente quando houver atingido a organização sindical em todos os seus níveis e ocorrerá de forma mais restrita quando juntos poderão ser encontrados certos níveis de pluralidade e de unicidade. Para exemplificar o pensamento do autor, essa coexistência demonstra-se quando em uma empresa for permitido que se vote apenas em um sindicato para representação de interesses dos obreiros, valendo, portanto, a unicidade no âmbito da empresa, mesmo que essa empresa esteja inserida em um sistema no qual vigore a pluralidade sindical. ${ }^{25}$

$\mathrm{Na}$ visão de Russomano ${ }^{26}$, que demonstra grande preferência pela pluralidade sindical, com ela finalmente pode ser atingida uma forma

\footnotetext{
${ }^{23}$ NASCIMENTO, Amauri Mascaro. Compêndio de direito sindical. 8. ed. São Paulo: LTr, 2015. p. 188.

${ }^{24}$ BORBA, Joselita Nepomuceno. Legitimidade concorrente na defesa dos direitos e interesses coletivos e difusos. São Paulo: LTr, 2013. p. 159.

${ }^{25}$ NASCIMENTO, Amauri Mascaro. Compêndio de direito sindical. 8. ed. São Paulo: LTr, 2015. p. 194.

${ }^{26}$ RUSSOMANO, Mozart Victor. Princípios gerais do direito sindical. 2. ed. Rio de Janeiro: Forense, 1998. p. 77.
} 
de organização sindical que seja de fato democrática, priorizando a liberdade integral.

É possível, ainda, a existência de um terceiro modelo, o da unidade sindical resultante de natural processo de associação. Trata-se de uma forma de organização na qual os sindicatos são reunidos conforme sua própria vontade pelo modelo da pluralidade sindical e no decorrer do tempo ocorre acomodação para uma união natural e facultativa dos membros que, ao invés de se unirem por meio de imposições legais concluem pela conveniência da união. Essa unidade encontra-se inteiramente em conformidade com a liberdade sindical, visto que se trata de uma opção dos sindicatos, embasada em sua plena liberdade de se reunirem conforme entenderem ser necessário. ${ }^{27} \mathrm{Na}$ unidade sindical, há a nítida manifestação de vontade e encontro de ideais entre os indivíduos, que buscam um mesmo objetivo, derivado de seus desígnios, sem que ocorram quaisquer imposições por meio do Estado. ${ }^{28}$

Mozart Victor Russomano aponta aspectos negativos e positivos da unicidade e da pluralidade sindicais. Segundo ele, a unicidade possui, como principal aspecto negativo, o fato de constituir um limite à liberdade sindical, além de se configurar como fruto da lei, impedindo formas espontâneas de agrupamentos sindicais, fato que pode até mesmo gerar desconfianças para o trabalhador em relação à independência das decisões sindicais. Não obstante as desvantagens desse sistema, o autor também evidencia pontos negativos envolvendo a pluralidade sindical, explanando que ela romperia com a unidade da classe de trabalhadores, ao mesmo tempo em que incentivaria a luta entre os sindicatos, fato que poderia causar grande desgaste e enfraquecimento a eles. Porém, mesmo possuindo aspectos negativos, visto que não há sistema que englobe somente qualidades, na visão do autor, o pluralismo sindical ainda consiste na melhor opção, ao modo que garante de maneira mais efetiva a liberdade dos sindicatos, além de proporcionar ao obreiro que possa escolher fazer parte do sindicato que lhe trouxer maior confiança. ${ }^{29}$

Qualquer modelo, unicidade ou pluralidade sindical, possui problemas a serem resolvidos. A unicidade pode comprometer a verdadeira representatividade do sindicato, uma vez que, sendo ou não representativo

\footnotetext{
${ }^{27}$ NASCIMENTO, Amauri Mascaro. Direito sindical. 2. ed. São Paulo: Saraiva, 1991. 241.

${ }^{28}$ NAHAS, Thereza Christina. Legitimidade ativa dos sindicatos. São Paulo: Atlas, 2001. p. 58.

${ }^{29}$ RUSSOMANO, Mozart Victor. Princípios gerais do direito sindical. 2. ed. Rio de Janeiro: Forense, 1998. p. 89-90.
} 
será ele o sindicato da categoria no qual todos os membros estão obrigatoriamente vinculados. A pluralidade pode pulverizar os sindicatos e enfraquecer a representatividade, mas depois de período de adaptação as próprias entidades sindicais podem convergir para a unidade e saírem fortalecidas desse processo. Por esta experiência de pluralidade sindical o Brasil não passou desde a inserção dos sindicatos na Carta Constitucional, na década de 1930.

\section{LIBERDADE SINDICAL NA CONSTITUIÇÃO FEDERAL DE 1988.}

A liberdade sindical plena representa a dimensão democrática dos sindicatos, inclusive no exercício da função representativa. Atendendo a proposta deste artigo, a liberdade sindical será analisada no âmbito da Constituição Federal de 1988 e no âmbito da OIT, precisamente na Convenção n. ${ }^{\circ} 87$.

A liberdade sindical expressa na Constituição Federal de 1988 tem dimensão individual e coletiva. Na primeira é assegurado a todos o direito de associar-se ou não ao sindicato e de manter-se associado ou não. Em sua dimensão coletiva a liberdade sindical assegura a não intervenção do Estado na criação e funcionamento do sindicato, de modo que, trabalhadores e empresas podem criar entidades sindicais em conformidade com seus interesses, elaborando estatutos e regras de funcionamento de acordo com a vontade da Assembleia Geral. Contudo, por imposição constitucional, a unicidade sindical deve ser observada na constituição de um sindicato ou entidade sindical.

Maurício Godinho Delgado acredita que com a Constituição de 1988 houve um nítido processo de transição democrática no que se refere ao aspecto da liberdade sindical e do sistema sindical como um todo, porém ocasionando uma fusão entre o afastamento de alguns itens do corporativismo do antigo modelo sindical com a manutenção de outros aspectos desse mesmo modelo. Desse modo, embora tenha sido afastada a possibilidade de intervenção político-administrativa do Estado, com ênfase na atuação das entidades sindicais na defesa dos interesses individuais e coletivos da categoria que representam, manteve-se o princípio da unicidade sindical. Na visão do autor, esse sincretismo entre heranças do corporativismo e aspectos de maior liberdade sindical apenas problematiza 
ainda mais o conflito de legitimidade e força do sistema sindical no Brasil, de modo que nada mais resta senão seguir-se para o remodelamento dos parâmetros sindicais brasileiros, a fim de que ele seja ajustado em conformidade com a plena liberdade sindical. ${ }^{30}$

A presença de elementos de liberdade sindical com elementos restritivos desta liberdade, notadamente unicidade sindical, categoria como critério obrigatório para a constituição de sindicato e base territorial mínima a ser observada, permitem a afirmação de ser nosso sistema sindical híbrido.

Russomano defende que a sindicalização livre consta em um direito natural e espontâneo do homem, sendo, então, o direito de associação uma condição básica para sobrevivência do indivíduo, integrante da própria liberdade. Seguindo esse raciocínio, o sindicato encontra-se como um segmento desse direito de associação, o qual permite que o trabalhador possa se associar e se retirar livremente dos sindicatos. No que tange à autonomia sindical, segundo ponto da liberdade sindical defendido pelo autor, tem-se que para que se configure, o sindicato não pode se sujeitar ao dirigismo de poderes alheios a ele. Com a autonomia, a entidade sindical pode formar novas entidades, organizar-se internamente da forma que lhe for mais conveniente, assim como pode formar entidades em grau superior, inclusive possibilitando a criação de centrais sindicais. Importante ressaltar que, embora a autonomia sindical deva ser ampla, ela não pode ser absoluta, visto que deve ser condicionada à ordem pública, em vias a evitar o descumprimento das finalidades sociais estipuladas a fim de se proteger toda uma coletividade maior. ${ }^{31}$

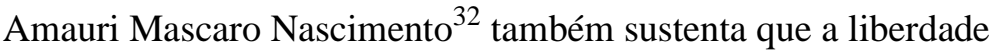
sindical, nos termos da Constituição Federal de 1988, constitui aspecto de certa complexidade, tendo em vista que por um lado adotou a liberdade sindical e por outro lado não adotou. A organização sindical brasileira não se encontra entre os sistemas de ampla liberdade, pois veda que seja criado mais de um sindicato na mesma base territorial e categoria, causando nítido entrave à autonomia sindical. A consequência da unicidade sindical é a natural e obrigatória exclusão da pluralidade sindical, portanto, fator limitador da liberdade sindical.

\footnotetext{
${ }^{30}$ DELGADO, Maurício Godinho. Curso de direito do trabalho. 13. ed. São Paulo: LTr, 2014. p. 1399.

${ }^{31}$ RUSSOMANO, Mozart Victor. Princípios gerais do direito sindical. 2. ed. Rio de Janeiro: Forense, 1998. p. 70-74.

${ }^{32}$ NASCIMENTO, Amauri Mascaro. Compêndio de direito sindical. 8. ed. São Paulo: LTr, 2015, 162164.
} 
O entendimento consentâneo em torno da liberdade sindical na Constituição Federal de 1988 demonstra a existência de aspectos positivos em alguns pontos e em outros não. Como formas de aplicações positivas da liberdade sindical no sistema brasileiro, encontra-se o artigo $8^{\circ}$, inciso I, no qual a liberdade está presente, bem como o inciso $\mathrm{V}$, do artigo $8^{\circ}$, que assegura a filiação e desfiliação dos indivíduos às entidades sindicais, não sendo imposto a eles que sejam parte do sindicato ou que permaneçam nele. Outro aspecto positivo é a autonomia sindical, garantindo o direito dos sindicatos de elaborarem seus próprios estatutos, regendo sua administração interna sem nenhuma interferência do Estado. A unicidade sindical é apontada como elemento negativo que obsta a plena liberdade sindical. ${ }^{33}$

A contribuição sindical obrigatória é frequentemente apontada como um dos pontos de restrição da liberdade sindical. Contudo, a Lei $n^{\circ}$ 13.467/2017 (conhecida como Reforma Trabalhista) tornou o pagamento desta contribuição facultativo, alterando vários dispositivos da CLT. O STF declarou ser constitucional a alteração legislativa e, por conseguinte, retirou da contribuição sindical ser perfil limitador da liberdade sindical.

A supressão da compulsoriedade da contribuição sindical advoga em favor da tese de que nosso sistema sindical está em fase de transição, no movimento em direção à plena liberdade sindical.

\subsection{LIBERDADE SINDICAL NA CONVENÇÃO № 87, DA OIT}

A Organização Internacional do Trabalho (OIT), criada em 1919, como parte do Tratado de Versalhes, tem por finalidade a justiça social, e por meio dela, defender a igualdade nas condições de trabalho e melhorar as próprias condições de trabalho. A liberdade sindical está presente desde a criação da OIT, expressa em seu preâmbulo. ${ }^{34}$

Dentre suas estipulações, a Organização Internacional do Trabalho determina que, para que se obtenha uma sociedade integralmente livre e aberta, é necessário que aos obreiros e empregadores seja permitido

\footnotetext{
${ }^{33}$ STURMER, Gilberto. A liberdade sindical na Constituição da República Federativa do Brasil de 1988 e sua relação com a Convenção 87 da Organização Internacional do Trabalho. Porto Alegre: Livraria do Advogado, 2007, p. 57-60.

34 INTERNATIONAL LABOUR ORGANIZATION - ILO. Disponível em: <http://www.ilo.org/global/ about-the-ilo/history/lang--es/index.htm>. Acesso em: 23 jul. 2017.
} 
criar suas próprias organizações e se afiliar a elas. Essas organizações desempenham um papel de grande relevância no que tange às melhorias democráticas de seus países. ${ }^{35}$

Estabelece a OIT que a liberdade de associação, a liberdade sindical e a liberdade de negociação coletiva são direitos fundamentais, os quais possuem suas bases na Constituição da Organização Internacional do Trabalho. A relevância desses direitos tem sido reafirmada internacionalmente, a exemplo da Declaração da OIT relacionada aos princípios e direitos fundamentais do trabalho, ocorrida em 1998. A Declaração da OIT sobre Justiça Social para uma Globalização Equitativa, adotada em 2008, indica que a liberdade sindical possui suma relevância para que os objetivos da Organização Internacional do Trabalho obtenham êxito. ${ }^{36}$

A OIT vem produzindo, ao longo de seus anos de funcionamento, uma série de documentos que dispõem sobre maneiras de se aperfeiçoar o direito dos trabalhadores em escala mundial. Dentre seus documentos de maior relevância (especialmente para o presente estudo), encontra-se a Convenção $n^{\circ} 87$ da OIT, de 1948, na qual a Organização delimita suas convicções acerca de como se formar um sistema sindical que garanta a ampla liberdade associativa. Nas palavras de Amauri Mascaro, essa Convenção é "a mais importante para a afirmação do princípio da liberdade sindical e da autonomia do sindicato perante o Estado". ${ }^{37}$

Em meio aos seus artigos, ressaltam-se os mais importantes, em relação ao presente tema: o artigo $2^{\circ}$, que elenca que trabalhadores e empregadores poderão constituir, sem necessidade de autorização, as organizações que desejarem, bem como a eles será permitido que se filiem a essas organizações, apenas com a condição de que respeitem seus estatutos. $\mathrm{O}$ artigo $3^{\circ}$ salienta a liberdade de gestão das organizações constituídas pelos obreiros e empregadores, na qual poderão redigir seus estatutos conforme entenderem ser mais razoável aos seus anseios, assim como poderão organizar suas atividades e escolher seus representantes sem nenhum óbice, além do fato de que é vedada qualquer forma de intervenção, por parte do Estado, que limite direitos ou atrapalhe o exercício das organizações. $\mathrm{O}$ artigo $4^{\circ}$ demonstra que não é permitido que

\footnotetext{
${ }^{35}$ Ibidem.

36 INTERNATIONAL LABOUR ORGANIZATION - ILO. Disponível em: <http://www.ilo.org/global/ about-the-ilo/history/lang--es/index.htm>. Acesso em: 23 jul. 2017.

${ }^{37}$ NASCIMENTO, Amauri Mascaro. Compêndio de direito sindical. 8. ed. São Paulo: LTr, 2015. p. 132.
} 
haja dissolução ou suspensão das organizações através da via administrativa, garantindo maior estabilidade a essas organizações. O artigo $5^{\circ}$ evidencia a permissão de que as organizações estabeleçam federações e confederações, assim como poderão se filiar a elas e, inclusive, permite que as federações e confederações se tornem filiadas das organizações internacionais de empregadores e obreiros. O artigo $6^{\circ}$ estipula que as disposições elencadas nos artigos $2^{\circ}, 3^{\circ}$ e $4^{\circ}$ também deverão ser aplicados às federações e confederações, demonstrando equilíbrio entre elas e suas respectivas organizações. $\mathrm{O}$ artigo $8^{\circ}$ determina que tanto os membros quanto as organizações devem, acima de tudo, respeitar a lei, a qual, evidentemente, não poderá ser aplicada de maneira a obstar as garantias da Convenção $n^{\circ} 87$. E, por fim, o artigo 10 salienta que o termo "organização" utilizado pela Convenção se refere a qualquer forma de organização de obreiros e empregadores que objetive defender seus direitos e interesses. ${ }^{38}$

Sérgio Pinto Martins entende que a Convenção $n^{\circ} 87$ da OIT apresenta uma variedade de garantias fundamentais, a exemplo do direito de empregadores e trabalhadores constituírem organizações conforme forem de sua escolha, sem necessidade de autorização do Estado. A Convenção é direcionada aos empregados e empregadores, mas também se dirige ao Estado quando estipula que o mesmo não poderá intervir nos sindicatos, sob pena de configurar-se ato atentatório à liberdade sindical. ${ }^{39}$

Existe outra Convenção da OIT que aborda o tema da liberdade sindical, trata-se da Convenção ${ }^{\circ} 98$. Esse documento traça linhas gerais sobre intromissões recíprocas entre obreiros e empregadores, estipula que deve haver proteção aos trabalhadores em relação aos atos que possivelmente atentem contra a liberdade sindical em meio à relação de emprego. Referida convenção veda a imposição, por parte do empregador, que o obreiro se filie ou deixe de se filiar a um determinado sindicato, além de elencar que o trabalhador não pode ser prejudicado por participar de atividades sindicais ou pela sua filiação a alguma entidade sindical. A Convenção $n^{\circ} 98$ foi ratificada pelo Brasil, posto que, seu conteúdo é totalmente compatível com a Constituição Federal e com o ordenamento jurídico interno como um todo.

\footnotetext{
${ }^{38}$ ORGANIZAÇÃO INTERNACIONAL DO TRABALHO - OIT. Disponível em: <http://www.ilo.org /brasilia/convencoes/WCMS_239608/lang--pt/index.htm> Acesso em: 23 jul. 2017.

${ }^{39}$ MARTINS, Sérgio Pinto. Direito do trabalho. 30. ed. São Paulo: Atlas, 2014. p. 777-778.
} 
Amauri Mascaro Nascimento destaca que a Organização Internacional do Trabalho condiciona grandes esforços em garantir a liberdade sindical, de maneira a trazer inspiração ao fomento do sindicalismo democrático. A Convenção $\mathrm{n}^{\circ} 87$ possui como objetivos a estipulação de padrões que baseiem as relações entre os Estados e os sindicatos, de forma a vislumbrar sempre a liberdade de união dos trabalhadores, assim como a autonomia interna das entidades sindicais, de maneira a criar uma proteção às organizações sindicais. ${ }^{40}$

A análise dos aspectos da liberdade sindical defendidos pela Organização Internacional do Trabalho, permite concluir que a pluralidade sindical é o modelo adotado, visto que a Convenção no 87 sempre objetivou que os sindicatos se formassem sem quaisquer possibilidades de intervencionismo estatal. No que toca às contribuições sindicais, a OIT sinaliza para que não sejam cobradas de maneira compulsória, defendendo que a contribuição para os sindicatos deve ser associativa, em observância aos estatutos de cada sindicato. Além disso, a OIT desautoriza o poder normativo da justiça também na esfera das negociações coletivas, ao ponto que acredita ser ele um entrave ao princípio do direito fundamental à liberdade. ${ }^{41}$

Leandro do Amaral frisa o aspecto da Convenção $n^{\circ} 87$ que se refere à multiplicidade das organizações sindicais, a qual determina a garantia da possibilidade de coexistir ao mesmo tempo mais de uma entidade sindical representando determinado grupo de trabalhadores em uma mesma base territorial. Na visão do autor, essa garantia é vislumbrada na Convenção supracitada como um "ideal jurídico-normativo", que prevê a livre instituição dos sindicatos de trabalhadores e empregadores, conforme julgarem conveniente e sem necessidade de prévia autorização estatal. Além disso, o autor também evidencia o aspecto da "diversidade representativa", o qual se distancia do modelo de sindicato único, afastando seu domínio e possibilitando que formas mais abrangentes e eficazes de representação coexistam. ${ }^{42}$

\footnotetext{
${ }^{40}$ NASCIMENTO, Amauri Mascaro. Compêndio de direito sindical. 8. ed. São Paulo: LTr, 2015. p. 132-133.

${ }^{41}$ STURMER, Gilberto. A liberdade sindical na Constituição da República Federativa do Brasil de 1988 e sua relação com a Convenção 87 da Organização Internacional do Trabalho. Porto Alegre: Livraria do Advogado, 2007, p. 140.

42 OLIVEIRA, Cinthia Machado de; DORNELES, Leandro do Amaral Dorneles de. Direito do trabalho. Porto Alegre: Verbo Jurídico, 2013. p. 378-379.
} 
O modelo de liberdade sindical adotado pela OIT é de liberdade plena, nesse sentido é a Convenção $n^{\circ} 87$ da OIT que acolhe como melhor sistema de liberdade sindical a pluralidade sindical, visto que não limita a representação sindical a um único sindicato representativo da mesma categoria profissional ou econômica dentro da mesma base territorial. Além disso, o modelo preconizado pela OIT foca na decisão livre de trabalhadores e empregadores para constituírem suas organizações sindicais, de maneira que sejam afastadas imposições e determinações legais que prejudiquem o livre exercício de sua liberdade.

Em alguns aspectos a Constituição Federal se aproximou da Convenção $n^{\circ}$ 87, da OIT, uma vez que a liberdade sindical individual foi implementada e a autonomia sindical foi assegurada pela não intervenção do Poder Público na organização e funcionamento do sindicato. Contudo, as restrições impostas pela Constituição Federal à liberdade sindical plena impossibilitam a ratificação da Convenção $n^{\circ} 87$, da OIT, visto a incongruência entre as duas normas.

Atualmente o maior entrave, talvez o único, à ratificação da Convenção da OIT $n^{\circ} 87$ pelo Brasil é a unicidade sindical imposta pela Constituição Federal de 1988. A unicidade sindical também foi entrave para a inclusão das Centrais Sindicais no sistema sindical confederativo. A unicidade sindical não é adotada pelas Centrais Sindicais, por conseguinte, as entidades sindicais dos trabalhadores podem se associar à Central que preferirem, independente da categoria e da base territorial. A liberdade nesse caso não diminuiu a força de representação das Centrais Sindicais, mas apenas concedeu liberdade de escolha para a associação. Talvez, esse fato seja emblemático para a adoção da liberdade sindical plena e possibilidade de ratificação da Convenção $n^{\circ} 87$, da OIT.

\section{CONSIDERAÇÕES FINAIS}

O tema central deste artigo é a liberdade sindical, analisada de forma comparativa na atual Constituição da República Federativa do Brasil e na Convenção $n^{\circ}$ 87, da OIT. No entanto, para melhor compreensão do assunto, alguns outros pontos foram abordados, tendo em vista que não se pode falar em liberdade sindical sem conhecer sindicato e suas origens, da mesma forma, as funções do sindicato justificam a necessidade da autonomia e da liberdade sindical. 
A liberdade sindical inserida na Constituição Federal de 1988 manteve algumas limitações originárias do modelo corporativista da década de 1930, quando os sindicatos foram inseridos em norma constitucional no Brasil. Em outros pontos, rompeu com o modelo original e avançou para forma mais democrática de atuação sindical. Nesse sentido, foi imposta a autonomia sindical e garantida a liberdade sindical individual. Contudo, a unicidade sindical foi mantida no texto constitucional.

Por sua vez, a liberdade sindical preceituada no âmbito da Organização Internacional do Trabalho é plena, sendo que sua Convenção n 87 adota o modelo da pluralidade sindical, antagônico ao sistema brasileiro mantido na atual Constituição Federal. De modo geral, os preceitos da Convenção $n^{\circ} 87$, da OIT superam de maneira positiva as determinações da Constituição Federal de 1988 sobre a liberdade sindical, visto que garantem maior autonomia aos sindicatos, fazendo com que sua função de representação possa ser melhor exercida, além de garantir uma democracia mais ampla em âmbito sindical.

A Convenção $n^{\circ} 87$ da OIT, via de consequência, é incompatível com o texto da Constituição Federal de 1988, razão pela qual, ainda não foi ratificada pelo Brasil.

\section{REFERÊNCIAS BIBLIOGRÁFICAS}

BARROS, Alice Monteiro de. Curso de direito do trabalho. 7 ed. São Paulo: LTr, 2011.

BORBA, Joselita Nepomuceno. Legitimidade concorrente na defesa dos direitos e interesses coletivos e difusos. São Paulo: LTr, 2013.

BRITO FILHO, José Cláudio Monteiro de. Direito sindical. 3. ed. São Paulo: LTr, 2009.

DELGADO, Maurício Godinho. Curso de direito do trabalho. 13. ed. São Paulo: LTr, 2014. Curso de direito do trabalho. 18. ed. São Paulo: LTr, 2019.

INTERNATIONAL LABOUR ORGANIZATION - ILO. Disponível em <http://www.ilo.org/global/about-the-ilo/history/lang--es/index.htm>. Acesso em: 23 jul. 2017.

MARTINS, Sérgio Pinto. Direito do trabalho. 30. ed. São Paulo: Atlas, 2014. p. 772.

NAHAS, Thereza Christina. Legitimidade ativa dos sindicatos. São Paulo: Atlas, 2001.

NASCIMENTO, Amauri Mascaro. Compêndio de direito sindical. 8. ed. São Paulo: LTr, 2015. 
Direito sindical. 2. ed. São Paulo: Saraiva, 1991.

OLIVEIRA, Cinthia Machado de; DORNELES, Leandro do Amaral Dorneles de. Direito do trabalho. Porto Alegre: Verbo Jurídico, 2013.

OLIVEIRA, Francisco Antônio de. Manual de direito individual e coletivo do trabalho. 2. ed. São Paulo: RT, 2000.

ORGANIZAÇÃO INTERNACIONAL DO TRABALHO - OIT. Disponível em: <http://www.ilo.org/brasilia/convencoes/WCMS_239608/lang--pt/index.htm> Acesso em: 23 jul. 2017.

RUSSOMANO, Mozart Victor. Princípios gerais do direito sindical. 2. ed. Rio de Janeiro: Forense. 1998.

STURMER, Gilberto. A liberdade sindical na Constituição da República Federativa do Brasil de 1988 e sua relação com a Convenção 87 da Organização Internacional do Trabalho. Porto Alegre: Livraria do Advogado, 2007. 